\title{
Subjective Social Indicators: Benefits and Limitations for Policy Making-An Introduction to this Special Issue
}

\author{
Heinz-Herbert Noll
}

Accepted: 30 June 2013/Published online: 12 July 2013

(C) Springer Science+Business Media Dordrecht 2013

\section{The Topic}

Although the field of empirical "happiness research" or the "new science of happiness"as it was overzealously named by Richard Layard-has been prospering in recent years and attracting considerable interest by policy makers, the usefulness of happiness indicators-or more generally subjective social indicators-for policy making purposes continues to be controversial: There are numerous advocates of the notion that subjective indicators can and should be used to better inform policy makers, but also many critical voices pointing to the ambivalent nature of this sort of information and indicators as well as to the risks of making use of them in everyday political decision making. The currently flourishing debate is all but new however. Particularly Scandinavian researchers representing a resources based notion of welfare or well-being have in their majority always been critical toward the use of subjective indicators for policy making purposes. According to Robert Erikson - one of the most eminent proponents of the Swedish "level of living approach"- "people's opinions and preferences should go into the democratic political process through their activities as citizens, but not through survey questions and opinion polls" (Erikson 1993: 78). Contrary to this position, happiness researchers have consistently underlined that policy makers need to take subjective indicators into account, at least in addition to objective indicators: “...subjective indicators are indispensable in social policy, both for assessing policy success and for selecting policy goals" (Veenhoven 2002: 40). Currently, those advocating the use of "happiness research"-results and measures of subjective well-being in the policy making process seem to outbalance those raising doubts whether "the scientific basis of happiness research (is) sufficiently strong to base important public policy considerations on it" (Whittington 2007). In recent years, it has not only been proposed to make use of this sort of research and information in specific policy making fields, e.g. health, or the labour market, but even to establish national accounts of (subjective) well-being (Diener et al. 2009; Michaelson et al. 2009). On the other hand, policy

H.-H. Noll ( $₫)$

Gesis - Leibniz Institute for the Social Sciences, P.O. Box 1221 55, 68072 Mannheim, Germany

e-mail: Heinz-Herbert.Noll@gesis.org 
makers seem to be uncertain as yet when it comes to the information potential of subjective well-being and other sorts of subjective social indicators and-apart from exceptionsoverall make use of them.

\section{Objective and Subjective Social Indicators}

The distinction between objective and subjective indicators as well as the current debate about their information potential can be traced back to the early days of social indicators research. While measures of the social reality, which are not filtered by perceptions and are independent from personal evaluations usually are considered as objective social indicators, subjective indicators are in contrast measures supposed to explicitly expressing subjective states, such as perceptions, assessments and preferences for example. According to Marc Abrams, one of the pioneers of research on subjective social indicators, "the 'objective world' is filtered through the individual's own perceptions and then weighted according to his expectations, experiences, attitudes, and present circumstances. These assessments have come to be called subjective social indicators" (Abrams 1973: 35). While there are obviously a whole lot of different methodological approaches available to be used to collect "objective data", subjective measurement apparently turns out to be restricted to the survey method. By generating subjective social indicators, respondents are not only addressed as neutral providers of information, but rather as persons characterized by specific needs, emotional states, personal experience, value orientations, preferences and so on. While the latter information can only be provided by the individual person concerned, "objective information" on living conditions, like housing space, household income or marital status, may also be observed by third parties, although this information frequently is being collected too by asking respondents in surveys directly.

The explicit debate on and usage of subjective social indicators goes back as far as to the early 1970s, when Campbell and Converse (1972) published a volume on "The Human Meaning of Social Change", which they considered to be complimentary to "Indicators of Social Change" (Sheldon and Moore 1968), another volume, which also was published within the series of the Russell Sage Foundation, but focusing on objective social indicators exclusively. Earlier than other social indicator pioneers, Campbell and Converse claimed that it was insufficient to monitor and chart social change by objective indicators only, but rather considered it equally important to address the sense people make of those changes "as well as the way these changes shape and determine the fine grain of human lives and gratification: in sum, the human meaning that these changes may be said to have" (Campbell and Converse 1972: 6). With his famous dictum that "ultimately, the quality of life must be in the eye of the beholder, and it is there that we seek ways to evaluate it", published in an article on "Aspiration, Satisfaction and Fulfillment" in the same volume, Campbell and Converse (1972: 442) laid the programmatic foundations for further research on subjective well-being and its measurement in years to come.

Much of the early research on subjective social indicators took place as part of those pioneering "Quality of Life Surveys", which were carried out in some countries during the 1970s: Among those surveys are the "American Quality of Life Survey" (Campbell et al. 1976), the "Quality of Life in Britain Survey" (Hall et al. 1973; Abrams 1973, 1976), the "Comparative Scandinavian Welfare Survey" (Allardt 1972) as well as the "German Welfare Survey" (Glatzer and Zapf 1984; Noll 2014a). These-by that time-new data collection programs did not only prepare the ground for empirical quality of life studies by providing innovative information on people's perceptions and assessments of their living 
conditions and life situation, but also stimulated conceptual and methodological research on subjective indicators and their measurement (Andrews and Withey 1976). Nowadays, the measurement of subjective quality of life issues is part of many national and supranational research driven surveys around the globe. ${ }^{1}$ More recently subjective social indicators have even found their way into surveys carried out by official statistical institutes, which in their majority expressed reservations against subjective measures in the past and thus turned out to be reluctant to include this sort of information into their regular statistical repertoire. ${ }^{2}$

Whilst indicators of subjective well-being, such as feelings of happiness and satisfaction, are most prominent examples of subjective indicators, there exist many other kinds of subjective measures as well. The broad class of subjective indicators does not only include also measures of subjective "ill-being" (e.g. stress or strain, anxiety, anomy, loneliness), but also indicators measuring expectations, perceptions and assessments of risks and opportunities, identification with social classes, nations or communities, value orientations and preferences, importance ratings, concerns as well as trust in persons and institutions. All of these different types of subjective indicators may provide most relevant information elements for a comprehensive quality of life measurement and may also contribute useful information inputs for policy making, although some of these kinds of indicators are less frequently used than others as yet.

\section{General Reservations Against Subjective Indicators}

Although the application of subjective indicators has been supported and endorsed by many researchers, there have also been critical voices all over the years advising against their usage, at least in policy making. Reservations against subjective indicators are-for example-referring to:

- Views that subjective indicators provide "soft" information rather than "hard statistical facts", which have been frequently expressed by various observers. Even Campbell and Converse in the introduction to their volume on the "Human Meaning of Social Change" consider subjective indicators as "so-called softer data of a more social-psychological sort" (Campbell and Converse 1972: 5) rather than "hard data". The qualification of subjective indicators as "soft data" usually implies some sort of degradation, challenging the credibility of this sort of information, or even their validity and reliability.

- Implicit as well as explicit doubts about the reliability and validity of subjective indicators are also all but new and have been addressed by numerous studies over the recent couple of decades, resulting in a large body of methodological research. ${ }^{3}$ Although there obviously exist significant differences between various individual measures, it seems to be fair to conclude, that subjective indicators are not by all means less valid and reliable than objective indicators in general. As far as reliability is concerned, a recent OECD report arrives at the result that "test-retest scores for measures of subjective well-being are generally lower than is the case for commonly collected statistics such as education and income, but higher than those found for more

\footnotetext{
1 For European supra-national surveys see e.g. Noll (2008).

2 See e.g. the articles by Hicks et al. and De Smedt in this special issue.

${ }^{3}$ For a most recent assessment of the validity of life-satisfaction scales see Diener et al. (2013).
} 
Table 1 Typology of welfarepositions

\begin{tabular}{lll}
\hline $\begin{array}{l}\text { Objective } \\
\text { living conditions }\end{array}$ & \multicolumn{2}{l}{ Subjective well-being } \\
\cline { 2 - 3 } & Good & Bad \\
\hline Good & Well-being & $\begin{array}{l}\text { Dissonance } \\
\text { Bad }\end{array}$ \\
\hline
\end{tabular}

cognitively challenging concepts (such as household expenditures)" (OECD 2013: 13). Assessing the validity of subjective well-being measures, the same report notices that "evidence strongly suggests that measures of both life evaluation and affect capture valid information" (OECD 2013: 13). In any case, there seems to be sufficient evidence that subjective indicators generally reach levels of reliability and validity, which make them "fit for purpose", including their potential usage in policy making. Interestingly, in a recent public debate on crime rates in German cities, the validity of objective indicators of public safety has been contested with reference to subjective indicators of perceived safety in the neighbourhood. ${ }^{4}$

- Concerns about weak correlations between objective and subjective indicators are also frequently expressed in order to substantiate reservations against the latter. It is argued that if correlations are weak, subjective information is of little indicator value, since it does not allow reliable direct inferences to the "reality". This kind of reasoning ignores however the possibility of different-and eventually even conflicting-notions of reality as well as the relevance of subjective perceptions and assessments for human action, which e.g. has been addressed by the so-called Thomas' theorem as early as in the 1920s: "If men define situations as real, they are real in their consequences" (Thomas and Thomas 1928: 572). In other words: subjective information on people's perceptions, assessments etc. bears its own value, even if it is not in accordance with impressions of an external "objective reality" based on objective measures. For example, perceptions of a high degree of insecurity in the neighbourhood will most likely have an impact on the behavior of persons, independent from their victimization risk in objective terms. Subjective indicators are thus not necessarily supposed to be strongly correlated with objective indicators and meant to replace them, but rather to be considered as alternative measures adding information value by providing complementary information elements not captured by objective indicators (Table 1).

From such a point of view, which seems to be shared by the majority of Quality of Life researchers, the combination of objective and subjective indicators has been considered as particularly interesting and promising. An early example, demonstrating the fruitfulness of such an approach, is a typology of four welfare-positions, resulting from a combination of objective and subjective dimensions and assessments of individual welfare or quality of life: The most desirable constellation of sound objective living conditions and positive subjective well-being is classified as "well-being". The combination of good living conditions and negative subjective well-being is characterized as "dissonance". Poor living conditions coinciding with low levels of subjective well-being represents a situation called deprivation. And finally, the constellation, in which poor living conditions go together with high degrees of subjective well-being is considered as "adaptation" (Zapf 1984: 25-26).

\footnotetext{
${ }^{4}$ See e.g. the interview with a councilor of the city of Frankfurt (in German) at the website of the major German TV news show "Tagesschau” (www.tagesschau.de/inland/kriminalstatistik134.html; accessed May 15, 2013).
} 
The two categories "adaptation", also known as the "satisfaction paradox", and "dissonance", also referred to as the "satisfaction dilemma", seem to be particularly interesting-even from a policy making point of view—not despite, but because the assessments based on objective and subjective information are contradictory rather than consistent. The "satisfaction paradox" results from low levels of aspirations and expectations or an adaptation of the latter to poor life circumstances in objective terms. In this case, findings of high levels of subjective well-being obviously should not be interpreted as an indication that there is no need for political action, but-in combination with objective indicatorswould rather allow to identify population groups, which may need support, but eventually would not raise their voice in the democratic political discourses and processes. ${ }^{5}$ On the other hand, the "satisfaction dilemma" points to the possibility that even improvements of living conditions resulting from political activities must not necessarily be appreciated by citizens, if the improvement does not fulfill their expectations or is being leveled out by rising expectations.

\section{The Current Debate About Indicators of Subjective Well-Being and Their Policy Use}

The current extensive debate over the potential benefits and limitations of making use of subjective indicators in the policy making process, also touches general concerns and reservations against subjective indicators as they just have been mentioned, but in addition addresses more specific issues too. However, this recent controversy is almost exclusively focusing at indicators of subjective well-being or even on life-satisfaction as an indicator of general individual happiness only (e.g. Bok 2010; Donovan and Halpern 2002; Duncan 2005), rather than addressing subjective indicators in general.

As a review of the relevant literature reveals, the controversy about the usability of subjective indicators for policy making purposes basically circles around a few key issues. One of these issues obviously is the question whether or not happiness or subjective well being is generally considered as desirable and should be maximized. Only if this were the case, increasing or declining happiness or satisfaction scores could unambiguously be interpreted as a positive or negative change in the well-being of individuals or the society as a whole. However, while the view that subjective well-being is a positive and desirable condition of a good life is shared by many, it has also been challenged by others. Some scholars not only draw the attention to the positive functions of dissatisfaction, for example when it comes to personal growth or the motivation to change a given unpleasant situation, but even argue that a good life is more than just a happy life. ${ }^{6}$ Particularly from the latter point of view, utilitarian or hedonistic understandings of subjective well-being have been contested and at the same time alternative notions, like "eudaimonic" concepts of wellbeing, have been proposed, which actually claim that "just feeling good is not good enough for a good life". 7

\footnotetext{
5 Referring to Hirschman's (1970) famous book "Exit, Voice and Loyalty", Campbell et al. (1976: 501) also argued, that "those who lack the skills to exercise voice are more likely to be heard from in a study of this type than in the normal workings of even a democratic political process".

${ }^{6}$ See for example various articles by Frank Furedi, a british sociologist and author, some of them published at the following website: www.frankfuredi.com/.

7 See Ilona Boniwell, "The concept of eudaimonic well-being” published at: http://www.positivepsychology. org.uk/pp-theory/eudaimonia/34-the-concept-of-eudaimonic-well-being.html.
} 
However, as Grant Duncan put it, "even if we assumed that happiness is the ultimate personal goal, happiness does not automatically become the ultimate political goal" (Duncan 2010: 12). It thus also seems to be quite controversial, whether or not happiness or the subjective well-being of individual citizens and its potential maximization should be addressed by governments and be considered a policy goal. Straightforward views, that "public policy should be about enhancing happiness or the welfare of people, now and in the future" (Ng and Ho 2006:1) are rejected by other scholars, like Duncan, who suggests, "that happiness maximization, as a social goal, is not an obligation of government" (Duncan 2010: 17). ${ }^{8}$ Those who are not in favor of pursuing happiness via public policies usually emphasize the private nature of life-satisfaction or happiness, or even express their concerns about a development toward a "Nanny State" attending to the feelings and mental states of citizens and thus warn against a therapeutic turn of politics, aiming to "manage emotions" rather than focusing at public issues (Furedi 2003). ${ }^{9}$

The controversy about happiness as a policy goal to be achieved by governments as well as the role of subjective indicators in the policy making process is closely related to the much older question of who knows best what is good for the people. Quite explicitly the traditional paternalistic approach, claiming that-within a democratic policy formation process-political elites and policy makers are generally better informed about what is good for people and thus are supposed to be able to take the right decisions, has been challenged by happiness researchers, assuming that "right actions ....are those that maximize happiness" (Duncan 2005: 23) and claiming "that the ultimate judge of happiness should be "whoever lives inside a person's skin"” (Lyubomirsky and Lepper 1999: 151). However, such a "grassroots approach" of policy making seems to have its limitations too, as Campbell et al. (1976: 501) noticed already as early as in the 1970s: “...the immediate felt wants of individuals involved in a situation are far from the only considerations that a truly enlightened policy formation process would need to take into account. The actors themselves are not typically endowed with anything like perfect information either as to the constraints of the situation in which they are operating or, for that matter, its possibilities". Against this background, policy makers, who normally are also far from disposing over perfect information, would seem to be well advised to take citizen's subjective perceptions and assessments into account as one among several information elements, but not to rely on this sort of information solely.

In the context of our considerations about the potential benefits and limitations of using subjective indicators for policy making, the most crucial controversial issue is perhaps the question, whether or not governments would be able to improve happiness or subjective well-being if they only wished. The majority of happiness researchers seem to give an affirmative answer to this question, among them scholars as eminent as Easterlin, Layard, and Veenhoven, who obviously believe that appropriate public policies can increase the average level of subjective well-being in a society. On this account, the majority of happiness researchers seem to suggest that available empirical evidence from their research allows "to uncover the kinds of socio-economic conditions and public policies that may maximize 'actual' welfare or happiness" (Duncan 2005: 19). However, there are also

\footnotetext{
${ }^{8}$ On this issue see also Frey and Stutzer (2000), who-from a different point of view-also advise against the "maximization of happiness".

9 Richard Layard's suggestion to employ larger numbers of therapists by the state and his proposal "that mental health should become the sixth pillar in the Welfare State" (Layard 2012: 4) have-among other clues-been interpreted as indications of such an eventual policy turn. Also some of the policy proposals based on theoretical considerations and findings from the field of "Positive Psychology" come close to therapeutic interventions.
} 
others, who principally deny the possibility of increasing the level of happiness via public policies: "happiness cannot be manufactured and standardised like happy meals. Nor can it be granted to us by benevolent policymakers. Why? Because genuine happiness is experienced through the interaction of the individual with the challenges thrown up by life. Mass-produced happiness is a contradiction in terms" (Furedi 2006). But even if we are leaving fundamental views like this aside, although certainly worth considering, happiness research itself points to major caveats, which are to some extent contesting the view that average happiness levels can be significantly and sustainably increased by policy makers. Two of those major obstacles have been nicely summarized in an article by Diener and Lucas (1999: 227) more than a decade ago: "The influence of genetics and personality suggests a limit on the degree to which policy can increase SWB" and "changes in the environment, although important for short-term well-being, lose salience over time through processes of adaptation, and have small effects on long-term SWB”.

The strong influence of more or less invariant genetic and personality factors has been uncovered yet in numerous empirical studies aiming to identify the determinants of individual subjective well-being. These studies also consistently demonstrate that only limited parts of the total variance in life-satisfaction and happiness scores-usually not more than $30 \%$ at best-are being explained by variables, which actually are in the reach of policy measures, such as labour market policies or educational and health programmes (e.g. Noll and Weick 2010). ${ }^{10}$

The adaptation issue - upward and downward — turns out to be the perhaps most serious problem faced by policy makers seeking to increase the level of subjective well-being within populations. ${ }^{11}$ This is why e.g. the so-called "setpoint theory", which assumes far reaching, if not perfect, psychological adaptation mechanisms, bringing individual happiness levels-after temporary deviations-ever back to their "personal setpoint", have been contested by scholars like Easterlin ${ }^{12}$ : "If the goal of public policy is to improve subjective well-being, this theory leads to a nihilistic view of economic and social policy. Setpoint theory implies that any measures taken to improve economic or social conditions can have only a transient effect on well-being, since each individual will in time revert to his or her given setpoint of happiness" (Easterlin 2003: 2). As a matter of fact, explanations of the observation that growth in income and wealth was not accompanied by corresponding increases of subjective well-being, which has been made in many countries and is known as the "Easterlin Paradox" (Easterlin 1974), usually also refer to adaptation processes, sometimes called "hedonic adaptation". In his extensive studies on this issue Easterlin arrives at the conclusion that processes of hedonic adaptation are particularly pronounced when it comes to people's material level of living, but much less so in other domains of life, like family life and health (Easterlin 2003: 25). Accordingly, he advises people to reallocate the use of their time in favor of family life and health in order to increase their individual happiness. However, if we look at the Easterlin Paradox from another angle, the observation of more or less unchanged levels of subjective well-being over longer periods of time does not only point to a missing longterm impact of income and

\footnotetext{
${ }^{10}$ For an explicit empirical analysis of the impact of labour market and health policies on life-satisfaction see the article by Boarini et al. in this special issue.

11 The adaptation issue has thus been raised already in the early days of the debate over subjective indicators. One of the reasons why Scandinavian researchers have been particularly critical toward "an approach based on people's own assessment of their degree of satisfaction is that it is partly determined by their level of aspiration" (Erikson 1993: 77).

${ }^{12}$ For another critical review of the set point theory see Headey (2008).
} 
wealth, but also raises doubts about the effect of all sorts of policies applied during the respective time periods, which in many cases have resulted in major improvements of living conditions in objective terms, such as reduced working hours, better education, longer life expectancy, usually considered as social progress (Noll 2014b). ${ }^{13}$ Following this observation, it seems as if it were quite likely that "the 'rising expectations' problem may apply to public policy as much as it does to economic growth. In other words, if governments take effective steps to improve social conditions and public services, this new standard then becomes the norm, and happiness surveys may reveal little sustained change" (Duncan 2005: 28). ${ }^{14}$

As we have seen, in the early days of social indicators research, even the advocates of subjective indicators usually arrived at the conclusion that these measures were supposed to play an import though limited role in the policy making process. Abrams, for example, noticed that "claims for the utility of perceptual indicators resides not in the argument that by themselves they can provide policy guidance and measures of policy evaluation, but that they are a necessary part, in conjunction with objective indicators, in any adequate process of societal decision making" (Abrams 1976: 9). Similarly, Campbell et al. (1976: 503) argued, that "direct information on actor satisfactions is merely one ingredient among many to be folded into the development of enlightened policy" and even more pessimistically concluded that "the limitations on policy use are numerous and fundamental" (p. 504).

Today we eventually observe a wider spectrum of opinions from strong support to radical refusal, but moderate views and suggestions of how to make use of subjective indicators for policy making purposes apparently still seem to prevail as Diener et al. recently observed: "Some argue that life-satisfaction measures should be at the very heart of policy, but most advocates for the scales argue that they can supplement and complement other indicators such as economic ones, but not replace them" (Diener et al. 2013: 521). In their own assessment Diener et al. suggest "that life-satisfaction measures have clear limits, and provide only one type of information to policy makers" (Diener et al. 2013: 521f).

\section{The Articles in this Special Issue at a Glance}

The articles assembled in this special issue will address some of the issues, which are currently subject of a broad debate, which has been briefly sketched in this introduction. The ten articles will discuss and assess the potential benefits of subjective indicators as well as their limitations for policy making purposes in different ways and from different angles. In a first section, three of the ten papers are discussing the "pros" and "cons" of subjective indicators of well-being at a conceptual and more fundamental level. While two of these papers argue in favor of the use of subjective indicators by policy makers, the third

\footnotetext{
${ }^{13}$ Interestingly, even in the Eastern part of Germany, where citizens have been exposed to major transformations of the political and economic system and have been subject to a whole range of policies under different governments during the last two decades, many of them bringing about considerable improvements of living conditions and material standards of living, the average life satisfaction of the East German population in 2011 was exactly at the same level as it was in 1990 (6.6 at a scale from 0 to 10; own calculations by GESIS-Social Indicators Research Centre based on SOEP data).

14 Doubts that satisfaction or happiness indicators are qualified to measure progress, result also from the fact that the answering scales used are closed rather than open ended, e.g. $0-10,1-7$, and thus-contrary to household income or GDP_do not allow unlimited increase of scale values.
} 
presents a critical view. In their article, Jan Delhey and Christian Kroll discuss six different ways of how indicators of subjective well-being can be used to inform the policy making process. They also present best practice examples of eventual policy usage and put them in context. Charles Seaford identifies a number of functions as part of the policy making process and argues that these functions are better fulfilled by subjective rather than objective social indicators. In contrast to these two articles, Jussi Simpura assumes the role of the "devil's advocate", presenting a critical view of subjective indicators and their use in policy making, which is rooted in the Scandinavian, resource based notion of welfare and well-being, considering subjective well-being primarily as a private rather than a public concern.

The following three articles are focusing at the potential and factual policy usage of subjective social indicators in three different European nations: The Netherlands, the United Kingdom and Italy. The article by Jeroen Boelhouwer and Cretien van Campen on "Steering towards happiness in the Netherlands" examines Dutch initiatives designed to promote happiness in fields such as municipal policy, health care, work and education and seeks to explore to which extent The Dutch government acts as a "happiness machine" and/or misfortune mitigator. Stephen Hicks, Lucy Tinkler and Paul Allin are presenting the recently developed Office for National Statistics' approach of measuring national wellbeing in the United Kingdom. They argue that subjective well-being measures have a potential role in the policy process alongside objective indicators and discuss how subjective indicators could be used in policy making in the United Kingdom. Carla Collicelli focuses at a more specific policy domain and seeks to explore the potential of subjective indicators in assessing health services as well as the social impact of administrative actions and public services more generally.

The article by Romina Boarini, Margherita Comola, Conal Smith, Robert Manchin, and Femke De Keulenaer addresses the crucial question whether or not governments are able to boost people's sense of well-being by analysing the impact of labour market and health policies on subjective well-being. The authors present empirical findings suggesting that specific policy measures affect life-satisfaction in a positive way, while others result in a reduction. In the following article, Orsolya Lelkes raises the question, whether public policy should better focus on minimising unhappiness rather than aiming to maximising happiness. The findings from an analysis of European data suggest to assume different causes of "bliss" and "misery". Thus, following her suggestions, policy makers seem to be well advised to give priority to policy measures, which are likely to be suitable for avoiding unhappiness.

The article by Eric Crettaz and Christian Suter seeks to examine whether and to which degree subjective indicators actually are affected by processes of downward adaptation, which may limit their policy usability considerably. The longitudinal analysis, which makes use of household panel data, demonstrates impressively that the bias caused by adaptation processes varies considerably among different measures used as indicators.

The final article in this special issue turns out to be somewhat different from the others. Marleen De Smedt addresses the issue of how subjective indicators have been adopted within the European Statistical System recently with a view to measure well-being and quality of life more comprehensively as a task of official statistics, and thus creating an important new data base for policy making purposes as well as academic research.

In sum, the articles assembled in this special issue are supposed to better inform the ongoing discussion about the benefits as well as limitations of subjective social indicators for policy making purposes and to bring this debate hopefully forward by adding informative evidence as well as new insights. 
Acknowledgments The majority of the articles published in this volume are based on papers presented at a conference on "Social Monitoring and Reporting in Europe 2012: Subjective Indicators-Usefulness and Information Potential for Policy Making", which took place at the Villa Vigoni, a German-Italian Centre of Excellence at the Como Lake in 2012. My sincere thanks go to the European Commission for the generous financial support of this conference and to the Villa Vigoni for the opportunity to discuss this momentous topic in a most beautiful and inspiring ambit. I'd also like to thank my colleagues Laura Camfield, Andrew Clark, Max Haller, Eric Harrison, Bruce Headey, Juergen Kohl, Peter Krause, Tadas Leoncikas and Claire Wallace, who acted as reviewers, for their most valuable work helping to improve the quality of the articles considerably. I am particularly grateful to Michaela Kurtov for all her great and careful work on preparing the manuscripts, and last but not least I'd like to thank Alex Michalos for his encouragement to publish this selection of articles in a special issue of Social Indicators Research.

\section{References}

Abrams, M. (1973). Research on subjective social indicators. In M. Nissel (Ed.), Social trends (Vol. 4, pp. 35-50). London: HMSO.

Abrams, M. (1976). A review of work on subjective social indicators 1971-1975. Social Science Research Council. Occasional Papers in survey Research No. 8. London.

Allardt, E., \& The Research Group for Comparative Sociology. (1972). The scandinavian welfare survey 1972. Data material. Tampere: Available at the Finnish Social Science Data Archive.

Andrews, F. M., \& Withey, S. B. (1976). Social indicators of well-being. New York: London.

Bok, D. (2010). The politics of happiness: What governments can learn from the new research on wellbeing. Princeton: Princeton University Press.

Campbell, A., \& Converse, P. (Eds.). (1972). The human meaning of social change. New York: Russell Sage Foundation.

Campbell, A., Converse, P., \& Rodgers, W. (1976). The quality of American life. New York: Russell Sage Foundation.

Diener, E., Inglehart, R., \& Tay, L. (2013). Theory and validity of life satisfaction scales. Social Indicators Research, 112(3), 497-527.

Diener, E., \& Lucas, R. E. (1999). Personality and subjective well-being. In D. Kahneman, E. Diener, \& N. Schwarz (Eds.), Well-being: The foundations of hedonic psychology (pp. 213-229). New York: Russell Sage Foundation.

Diener, E., Lucas, R. E., Schimmack, U., \& Helliwell, J. F. (2009). Well-being for public policy. Oxford/ New York: Oxford University Press.

Donovan, N., \& Halpern, D. (2002). Life satisfaction: The state of knowledge and implications for government. London: Prime Minister's Strategy Unit.

Duncan, G. (2005). What do we mean by 'happiness'? The relevance of subjective wellbeing to social policy. Social Policy Journal of New Zealand, 25, 16-31.

Duncan, G. (2010). Should happiness-maximization be the goal of government? Journal of Happiness Studies, 11(2), 163-178.

Easterlin, R. A. (1974). Does economic growth improve the human lot? Some empirical evidence. In P. A. David \& M. W. Reder (Eds.), Nations and households in economic growth (pp. 89-125). New York: Academic Press.

Easterlin, R. A. (2003). Building a better theory of well-being. IZA Discussion Papers, No. 742. Bonn.

Erikson, R. (1993). Descriptions of inequality: The Swedish approach to welfare research. In M. Nussbaum $\&$ A. Sen (Eds.), The quality of life (pp. 67-87). Oxford: Clarendon Press.

Frey, B. S., \& Stutzer, A. (2000). Maximizing happiness? German Economic Review, 1(2), 145-167.

Furedi, F. (2003). Therapy culture. London: Routledge.

Furedi, F. (2006). Why the 'politics of happiness' makes me mad. Published at: www.spiked-online.com/ index.php?/site/article/311/. Accessed June 10, 2013.

Glatzer, W., \& Zapf, W. (Eds.). (1984). Lebensqualität in der Bundesrepublik, 13-26. Frankfurt a.M./New York: Campus.

Hall, J., Lord, D., Marsh, C., \& Ring, J. (1973). Quality of life survey (Urban Britain: 1973). London: SSRC-Survey Unit.

Headey, B. (2008). Life goals matter to happiness: a revision of set-point theory. Social Indicators Research, 86, 213-231.

Hirschman, A. O. (1970). Exit, voice and loyalty, responses to decline in firms, organizations and states. Cambridge MA: Harvard University Press. 
Layard, R. (2012). Mental health: The new frontier for the welfare state. In CEP 21st birthday lecture series, 06 March 2012, London. Available at: http://eprints.lse.ac.uk/47418/. Accessed June 7, 2013.

Lyubomirsky, S., \& Lepper, H. S. (1999). A measure of subjective happiness: Preliminary reliability and construct validation. Social Indicators Research, 46, 137-155.

Michaelson, J., Abdallah, S., Steuer, N., Thompson, S., Marks, N., Aked, J., et al. (2009). National accounts of well-being: Bringing real wealth onto the balance sheet. London: New Economics Foundation.

$\mathrm{Ng}$, Y.-K., \& Ho, L. S. (2006). Introduction: Happiness as the only ultimate objective of public policy. In Y.-K. Ng \& L. S. Ho (Eds.), Happiness and public policy: Theory, case studies and implications (pp. 1-16). New York: Palgrave Macmillan.

Noll, H.-H. (2008). European survey data: Rich sources for quality of life research. In V. Møller, et al. (Eds.), Barometers of quality of life around the globe social indicators research series (Vol. 33, pp. 1-21). Dordrecht: Springer.

Noll, H.-H. (2014a). The German Welfare Survey. In A. C. Michalos (Ed.), Encyclopedia of quality of life and well-being research (in press). Dordrecht: Springer.

Noll, H.-H. (2014b). Societal Progress. In A. C. Michalos (Ed.), Encyclopedia of quality of life and wellbeing research (in press). Dordrecht: Springer.

Noll, H.-H., \& Weick, S. (2010). Subjective well-being in Germany: Evolutions, determinants and policy implications. In B. Greve (Ed.), Happiness and social policy in Europe, 70-88. Cheltenham: Edward Elgar.

OECD. (2013). OECD Guidelines on Measuring Subjective Well-being. Paris: OECD Publishing. doi: 10.1787/9789264191655-en.

Sheldon, E. H., \& Moore, W. E. (Eds.). (1968). Indicators of social change: Concepts and measurements. New York: Russell Sage Foundation.

Thomas, W. I., \& Thomas, D. S. (1928). The child in America: Behavior problems and programs. New York: Knopf.

Veenhoven, R. (2002). Why social policy needs subjective indicators. Social Indicators Research, 58, $33-45$.

Whittington, S. (2007). An inquiry into the nature and causes of the happiness of nations. Policy, 23(4), 44-46.

Zapf, W. (1984). Individuelle Wohlfahrt: Lebensbedingungen und wahrgenommene Lebensqualität. In W. Glatzer \& W. Zapf (Eds.), Lebensqualität in der Bundesrepublik (pp. 13-26). Frankfurt a.M./New York: Campus. 